\title{
Distribution of gp138, a cell surface protein responsible for sexual cell fusion, among cellular slime moulds
}

\author{
Kazuhiro Aiba, Kaichiro Yanagisawa and Hideko Urushihara* \\ University of Tsukuba, Institute of Biological Sciences, Tsukuba, Ibaraki 305, Japan
}

(Received 23 June 1992; revised 21 September 1992; accepted 5 October 1992)

\begin{abstract}
Sexual cell fusion occurs between NC4 and HM1, heterothallic strains of Dictyostelium discoideum. Several cell surface proteins relevant to the process have been identified. One of them, gp138, exists in fusion-competent cells of both NC4 and HM1, and is considered to be more concerned with membrane fusion than gamete recognition. In this study, we raised monoclonal antibodies against gp138 and examined gp138 distribution among strains and species of cellular slime moulds to confirm its importance in sexual cell fusion. All heterothallic and bisexual $D$. discoideum strains examined were found to possess gp138, while asexual and homothallic strains lacked it. The anti-gp138 monoclonal antibody detected several distinct proteins in homothallic strains and one in an asexual strain. Some of the former proteins appeared together with the increase in binucleated cells. Cells of Dictyostelium mucoroides and Polysphondylium pallidum did not possess proteins reactive to the monoclonal antibody. These results indicate that gp138 is common among, but restricted to, cross-matable strains of $D$. discoideum. Our results also support previously published molecular phylogenetic studies which suggest that homothallic and asexual strains of $D$. discoideum are remote from other strains of $D$. discoideum but are less distantly related to them than other species are.
\end{abstract}

\section{Introduction}

Sexual reproduction provides a means for shuffling genetic material. Without it, accumulation of advantageous mutations would be much slower (Kirkpatrick \& Jenkins, 1989) and deleterious ones could not easily be eliminated (Kondrashov, 1988). Analysis of the origin and evolution of sexuality, therefore, is an interesting and important subject of basic biology, but its molecular basis is not well documented. Although molecular mechanisms of sexual cell fusion are being elucidated in several lower (Luporini \& Heckmann, 1990; Herskowitz, 1989; Glabe et al., 1991) and higher organisms (Sidhu \& Guraya, 1991), very little phylogenetic analysis has been carried out.

The soil amoebae of the cellular slime moulds are unique and useful organisms for the study of sexual phenomena. They feed on bacteria and propagate by fission, while in due course they enter into the sexual cycle called macrocyst formation (Blaskovics \& Raper, 1957; MacInnes \& Francis, 1974). Entrance into the sexual cycle is controlled by environmental factors such as light and excess water (Nickerson \& Raper, 1973; Erdos et al., 1976). The mating system of cellular slime

*Author for correspondence. Tel. 029853 4910; fax 0298536614. moulds is polymorphic. Heterothallic, homothallic, bisexual and asexual strains have all been found in Dictyostelium discoideum (Erdos et al., 1973; Robson \& Williams, 1980) and alternate homothallism (Blaskovics \& Raper, 1957) or heterothallism (Clark et al., 1973; Erdos et al., 1975; Francis, 1975) have been described in other species.

We have been studying the molecular aspects of sexual cell fusion in macrocyst formation using NC4 and HM1, complementary heterothallic strains in $D$. discoideum. Several cell surface components with possible relevance to the cell fusion between these strains have been identified (for a review, see Urushihara, 1992). One of these, gp138, has been shown to be a target antigen for cell-fusion-inhibiting antibodies (Suzuki \& Yanagisawa, $1989 b$ ) and has been purified and characterized (Suzuki $\&$ Yanagisawa, 1990). This protein is detected in fusioncompetent cells of both HM1 and NC4 and is therefore suspected to be responsible for membrane fusion and not for gamete recognition.

In this study, we raised monoclonal antibodies against gp138 and examined whether $D$. discoideum strains other than NC4 and HM1, and species other than D. discoideum, possessed gp138. It was widespread among heterothallic and bisexual strains in $D$. discoideum. Homothallic and asexual strains of $D$. discoideum lacked 
gp138 but retained proteins which shared the epitope to the antibody with gp138; other species did not.

\section{Methods}

Organisms and culture methods. NC4 (mat A) and HM1 (mat a, derived from V12) are heterothallic strains of $D$. discoideum and their mating properties have been described in detail (Suzuki \& Yanagisawa, $1989 a$ ). WS472, WS583 and WS655 are $m a t A$ and WS7 and WS656 are mat a strains of $D$. discoideum (Erdos et al., 1973; Robson \& Williams, 1979), and were kindly provided by Dr K. Williams (Macquarie Univ., NSW, Australia). WS2162 and WS112B, bisexual strains which form macrocysts with either mat $A$ or mat a strains (Robson \& Williams, 1980), and WS584, an asexual strain without sexual potency (Erdos et al., 1973), were gifts from Dr Welker's laboratory (Utah State Univ., USA). AC4 (Cavender \& Raper, 1968) and ZA3A (Robson \& Williams, 1980) are homothallic strains. These asexual and homothallic strains have been classified as being $D$. discoideum from morphological criteria, their fruiting bodies having discs at the bottom of the stalks, but recently this classification has been questioned (Briscoe et al., 1987; Evans et al., 1988) (see Discussion for details).

The Dm7 strain of Dictyostelium mucoroides (MacInnes \& Francis, 1974) is homothallic and was provided by Dr Amagai (Tohoku Univ., Aoba, Sendai, Japan). A heterothallic strain of Polysphondylium pallidum, CK8 (Mizutani et al., 1990), was isolated by Hagiwara. The names and mating properties of the strains used, which were confirmed at the beginning of the study, are given in Table 1. Each strain was maintained as fruiting bodies on nutrient SM-agar plates (Sussman, 1966) with Klebsiella aerogenes as a food source.

Preparation of fusion-competent cells. To obtain cells competent for sexual cell fusion (fusion-competent cells), growth-phase cells on SMagar plates were cultured at $22^{\circ} \mathrm{C}$ in a shaken liquid medium in darkness for $15 \mathrm{~h}$ unless otherwise stated. This cultured has been shown to render NC4 and HM1 cells capable of immediate cell fusion (Saga et al., 1983).

Partial purification of gp138. gp138 was partially purified using WGA affinity columns (Suzuki \& Yanagisawa, 1990). Cell ghosts (crude membrane fraction) (Sussman \& Boschwitz, 1975) were prepared from fusion-competent NC4 cells and solubilized in a Tris buffer (10 mM-Tris $/ \mathrm{HCl}, \mathrm{pH} 7.4)$ containing $0.5 \%$ cholic acid and $0.5 \%$ deoxycholic acid and centrifuged at 14000 r.p.m. for $10 \mathrm{~min}$. The supernatant was recentrifuged for clarification and loaded onto a column of WGA-agarose equilibrated with the Tris buffer containing $0.15 \%$ deoxycholic acid (DOC-Tris). After extensive washing with DOC-Tris, the bound fraction was eluted with DOC-Tris containing $0 \cdot 2 \mathrm{M}-N$-acetyl-D-glucosamine.

Raising and screening hybridomas. Partially purified gp138 was intraperitoneally injected into BALB/c mice together with aluminium hydroxide as adjuvant. After three weeks, the same quantity of gp138 was injected into their eye sockets. Three days later, the mice splenocytes were fused with P3U1 (P3X63Ag8-U1) myeloma cells by the conventional hybridoma technique. The resulting hybridomas were first screened for production of antibodies that bound to partially purified gp138 by the enzyme-linked immunosorbent assay. The selected hybridomas were further screened for specificity to gp 138 by immunoblotting. Positive hybridomas were then cloned by plating at the limiting dilution.

Gel electrophoresis and immunoblotting. Slab SDS-PAGE was performed by the method of Laemmli (1970) with minor modifications. For immunoblotting, proteins in a gel were transferred to a nitrocellulose membrane $(0.45 \mu \mathrm{m}$, Schleicher \& Schuell), which was then incubated with antibodies for $1 \mathrm{~h}$ at room temperature. The membrane was further incubated with peroxidase-conjugated anti- mouse IgG (Jackson) or protein A (EY Laboratories) for another hour and then developed with $0.03 \%$ diaminobenzidine.

Nuclear staining. To estimate the extent of cell fusion in the culture of homothallic strains, aliquots of cell suspension were taken for nuclear staining with Hoechst 33258 by the method described previously (Urushihara et al., 1990). Numbers of cells with 1,2,3 and more nuclei were counted and the percentage of nuclei in multinucleated cells to the total number of nuclei was calculated and used as the index of cell fusion. Duplicates of more than 200 cells were examined for each sample.

\section{Results}

\section{Specificity of the anti-gp138 monoclonal antibody}

Five monoclonal antibodies specific to gp138 were obtained. One of them, EF11, was used for this study. It gave a single band in immunoblots of both total proteins of fusion-competent NC4 cells and of partially purified gp138 (Fig. 1). This band comigrated with gp138 detected by FRA-6, a rabbit antiserum raised against purified gp138 (Suzuki \& Yanagisawa, 1990). Specificity of EF11 to gp138 was confirmed also by two-dimensional gel electrophoresis by the methods of Hirabayashi (1981) (data not shown).

\section{Detection of $g p 138$ in heterothallic strains of D. discoideum}

Various heterothallic strains of $D$. discoideum were examined for expression of gp138 after cultivation in a liquid medium for $15 \mathrm{~h}$ in darkness (Fig. 2). EF11

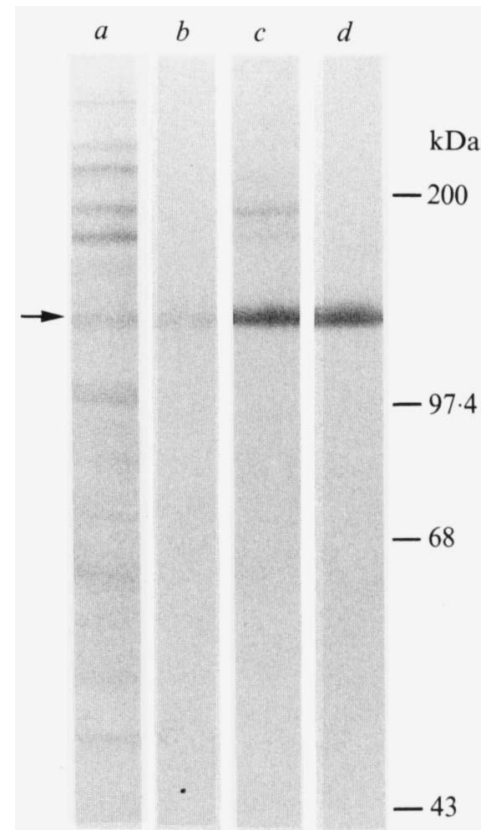

Fig. 1. Specificity of EF11, an anti-gp138 monoclonal antibody. Whole proteins of fusion-competent NC4 cells ( $a$ and $b$ ) and partially purified gpl38 ( $c$ and $d$ ) were subjected to SDS-PAGE and immunostained either with FRA-6 antiserum ( $a$ and $c$ ) or with EF11 ( $b$ and $d$ ). The arrow indicates the position of gp 138 . 


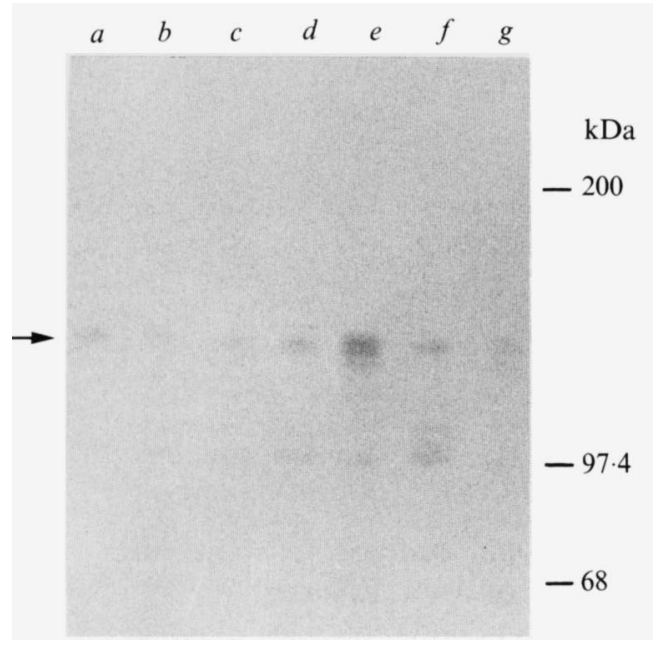

Fig. 2. Detection of gp138 in heterothallic strains of $D$. discoideum. Whole proteins obtained from $1 \times 10^{5}$ fusion-competent cells of $(a)$ NC4, (b) WS472, (c) WS583, (d) WS655, (e) HM1, (f) WS7, and (g) WS656 were subjected to SDS-PAGE, transferred to nitrocellulose membrane and immunostained with EF11. Lanes $a-d$ are mat $A$, and e-g mat a strains. The arrow indicates the position of gp138. detected gp138 in HM1. This is in accord with the previous finding that, although gp138 was first identified in NC4, it exists also in HM1 (Suzuki \& Yanagisawa, $1989 b$ ). Furthermore, all other heterothallic strains in D. discoideum examined also possessed gp138. These included both mat $A$ (WS472, WS583 and WS655) and mat a strains (WS7 and WS656). An additional band of about $95 \mathrm{kDa}$ is seen in Fig. 2 but it appeared without reproducibility. This band seems to be due to background staining. Except for this, gp138 was the only protein that reacted with EF11 in all the heterothallic strains shown in Fig. 2.

\section{Reactivity of anti-gp138 antibody with other strains of D. discoideum}

We extended the examination to nonheterothallic strains, that is, bisexual, homothallic and asexual strains which had been morphologically assigned to $D$. discoideum. As can be seen in Fig. 3, a bisexual strain, WS2162, possessed gp138 as the only band detected by EF11.

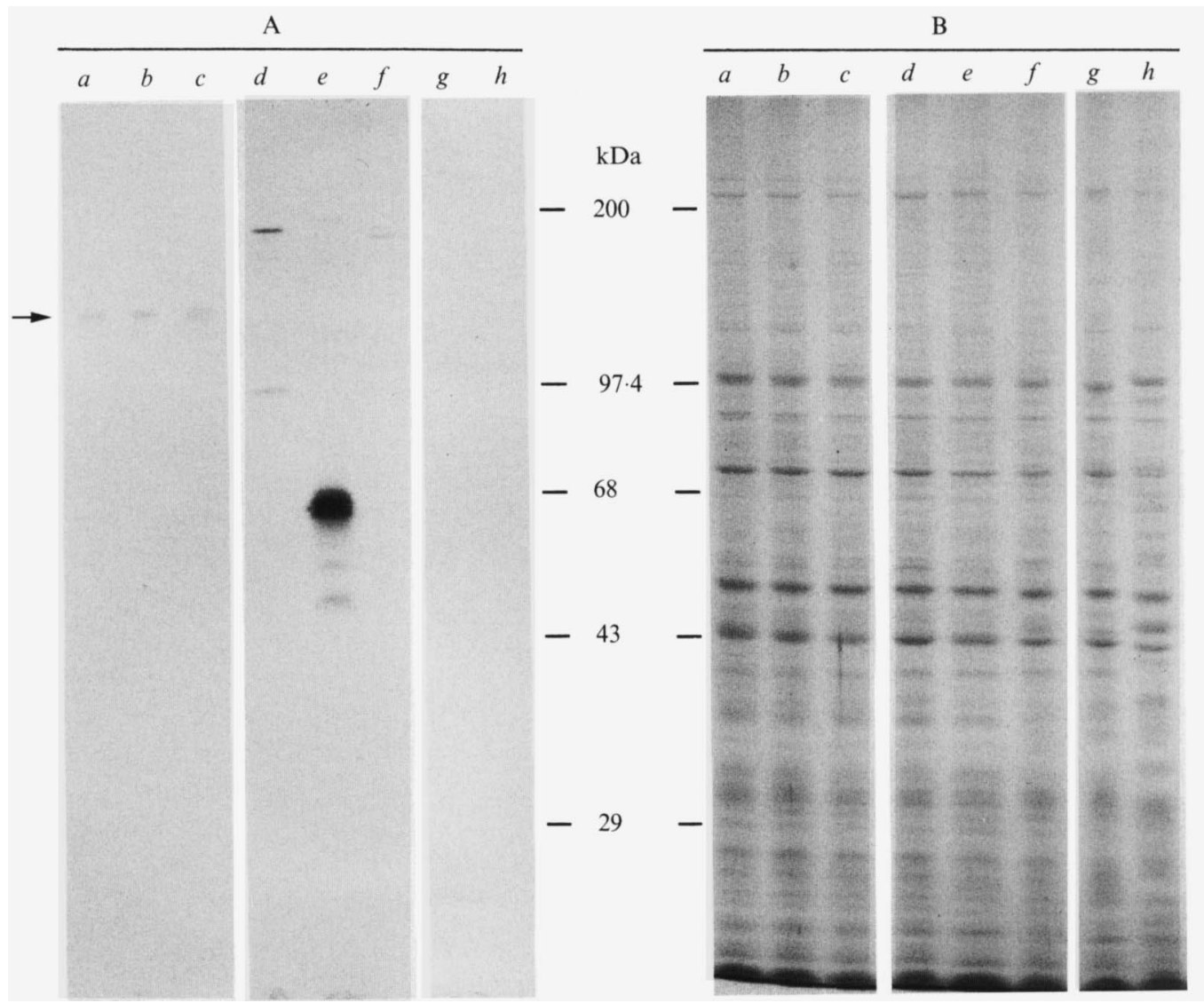

Fig. 3. Detection of gp138 in atypical strains of $D$. discoideum and in other species. Cells were cultured in a shaken liquid medium to render them fusion-competent as described in Methods. Whole proteins obtained from $1 \times 10^{5}$ cells of $(a)$ NC4, $(b)$ WS2162, (c) WS112B, $(d) \mathrm{AC4},(e) \mathrm{ZA} 3 \mathrm{~A},(f) \mathrm{WS} 584,(g) \mathrm{Dm} 7$ and $(h) \mathrm{CK} 8$ were subjected to SDS-PAGE and either transferred to nitrocellulose membrane for immunostaining with EF11 (A) or directly stained with CBBR (B). The arrow indicates the position of gp138. 

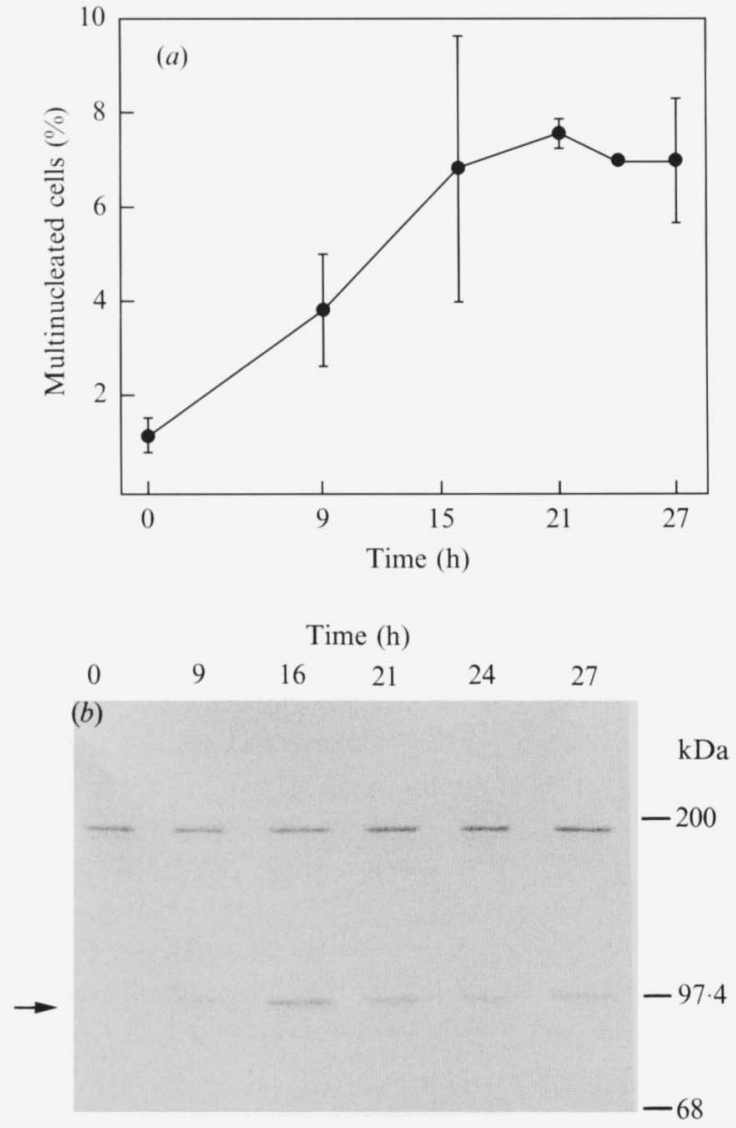

Fig. 4. Time course of multinucleated-cell formation $(a)$ and appearance of EF11-reactive proteins $(b)$ in a liquid culture of AC4 cells. Cells on SM-agar plates were cultured in a liquid medium at $22^{\circ} \mathrm{C}$ in darkness. At the times indicated, cells were taken for nuclear staining and for SDS-PAGE followed by immunostaining with EF11. In (a) duplicate samples were examined and their means were plotted. Standard deviations are shown by bars. The arrow in $(b)$ indicates a band appearing in parallel with formation of multinucleated cells.

Another bisexual strain, WS112B, gave similar results except that the band of gp138 tended to be somewhat broader. This tendency was also observed in HM1 (for example, lane $e$ in Fig. 2) but not in NC4 or WS2162.

In contrast to the strains mentioned above, homothallic and asexual strains gave entirely different results. EF11 appeared to react with proteins of distinct molecular mass from gp138 in the immunoblot of homothallic strains, AC4 and ZA3A, and an asexual strain, WS584. AC4 possessed two EF11-reactive proteins of 190 and $96 \mathrm{kDa}$. ZA3A possessed a $66 \mathrm{kDa}$ protein with enormous reactivity to EF11 and several proteins of $195,57,52$, and $46 \mathrm{kDa}$ with much weaker reactivity, while WS584 possessed a single EF11-reactive protein of $185 \mathrm{kDa}$.

Those EF11-reactive bands in AC4 and ZA3A may be related to sexual cell fusion. Alternatively, they might simply share the epitope to EF11 with gp138, having
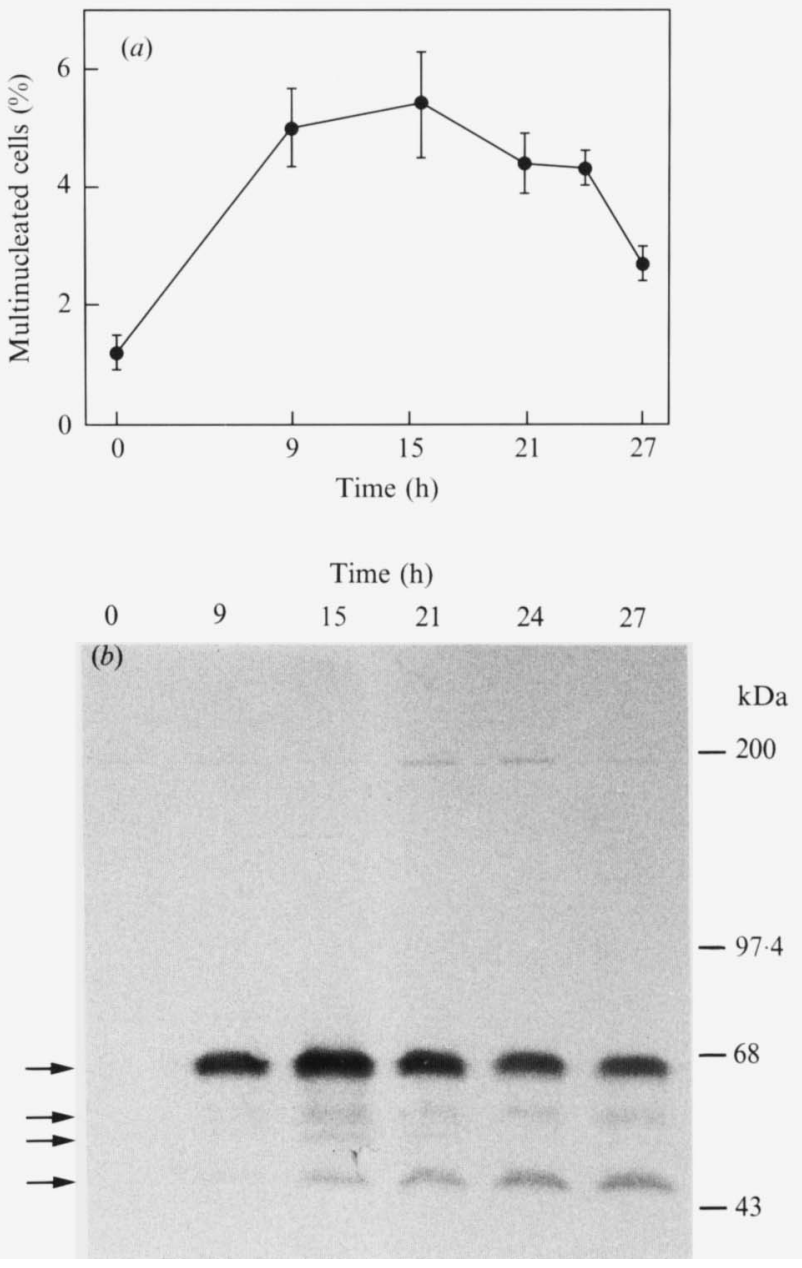

Fig. 5. Time course of multinucleated-cell formation ( $a$ ) and appearance of EF11-reactive proteins $(b)$ in a liquid culture of ZA3A cells. Cells on SM-agar plates were cultured in a liquid medium at $22^{\circ} \mathrm{C}$ in darkness. At the times indicated, cells were taken for nuclear staining and for SDS-PAGE followed by immunostaining with EF11. In (a) duplicate samples were examined and their means were plotted. Standard deviations are shown by bars. Arrows in $(b)$ indicate bands appearing in parallel with formation of multinucleated cells.

nothing to do with cell fusion. In order to clarify this point, occurrence of cell fusion and expression of EF11-reactive proteins in these strains were examined in parallel. To do this, growth-phase cells on SM-agar plates were cultured in a liquid medium in darkness, and at appropriate times, a small number of cells were taken from the culture and processed for nuclear staining to detect multinucleated cells and for electrophoresis to detect EF11-reactive proteins.

As shown in Fig. 4(a) the multinucleated cells in AC4 were barely above $1 \%$ at time 0 ; these probably represent cells in mitosis. The percentage of multinucleated cells gradually increased with time and reached a plateau at around $16 \mathrm{~h}$. In the immunoblotting pattern of AC4 (Fig. $4 b$ ), the $96 \mathrm{kDa}$ band was absent at time 0 , 
Table 1. Detection of proteins reactive to the anti-gp138 monoclonal antibody

\begin{tabular}{|c|c|c|c|c|}
\hline \multirow[b]{2}{*}{ Species* } & \multirow[b]{2}{*}{ Strain } & \multirow[b]{2}{*}{ Mating property } & \multicolumn{2}{|c|}{$\begin{array}{c}\text { EF11-reactive } \\
\text { protein } \dagger\end{array}$} \\
\hline & & & gp138 & Other $\ddagger$ \\
\hline \multirow[t]{12}{*}{ D. discoideum } & NC4 & Heterothallic (mat $A$ ) & t & - \\
\hline & WS472 & Heterothallic (mat $A$ ) & + & - \\
\hline & WS583 & Heterothallic (mat $A$ ) & + & - \\
\hline & WS655 & Heterothallic (mat $A$ ) & + & - \\
\hline & HM1 & Heterothallic (mat a) & + & - \\
\hline & WS7 & Heterothallic (mat $a$ ) & + & - \\
\hline & WS656 & Heterothallic (mat a) & + & - \\
\hline & WS2162 & Bisexual & + & - \\
\hline & WS112B & Bisexual & + & - \\
\hline & AC4 & Homothallic & - & + \\
\hline & ZA3A & Homothallic & - & + \\
\hline & WS584 & Asexual & - & + \\
\hline D. mucoroides & $\operatorname{Dm} 7$ & Homothallic & - & - \\
\hline P. pallidum & CK8 & Heterothallic & - & - \\
\hline
\end{tabular}

* Assignment of homothallic and asexual strains to $D$. discoideum does not seem to be appropriate (see text) but morphological classification is adopted in this instance.

$\dagger+$ and - indicate the presence and absence of EF11-reactive proteins, respectively.

$\ddagger$ Molecular masses of the reactive proteins were, 190 and $96 \mathrm{kDa}$ in AC4, $195,66,57,52$ and $46 \mathrm{kDa}$ in ZA3A, and $185 \mathrm{kDa}$ in WS584.

appeared from $9 \mathrm{~h}$ of cultivation and was most intense at $16 \mathrm{~h}$, while the $190 \mathrm{kDa}$ band was detected at $0 \mathrm{~h}$ and its intensity remained fairly constant throughout the culture period. Very similar parallelism was observed in ZA3A. At time 0 , only the $195 \mathrm{kDa}$ band was present and the major $66 \mathrm{kDa}$ band and less intense bands below it appeared at $9 \mathrm{~h}$ (or $15 \mathrm{~h}$ for faint bands), and became most intense at $15 \mathrm{~h}$ (Fig. $5 b$ ) in correspondence with the increase of multinucleated cells (Fig. 5a). The faint bands below the $66 \mathrm{kDa}$ band might be its degradation products, but this is still uncertain. Thus, expression of the $96 \mathrm{kDa}$ protein in $\mathrm{AC} 4$ and the $66 \mathrm{kDa}$ protein and the lower-molecular-mass bands in ZA3A apparently correlated with the formation of multinucleated cells in those strains. These proteins may be related to sexual cell fusion of the relevant strains. gp138 was not detected at any time of the culture period in either one of the homothallic strains. Since the asexual strain did not undergo sexual cell fusion to produce multinucleated cells, it was not possible to assess the relationship of the $185 \mathrm{kDa}$ band in WS584 to sexual cell fusion.

\section{Absence of EF11-reactive proteins in species other than D. discoideum}

Strains of different species from $D$. discoideum, $\mathrm{Dm} 7$ in Dictyostelium mucoroides and CK8 in Polysphondylium pallidum, were examined. Fusion-competent cells of Dm7 and CK8 were obtained by culturing cells in liquid for $18 \mathrm{~h}$ and $17 \mathrm{~h}$, respectively, and were subjected to SDSPAGE. When the electrophoresis gel was stained with Coomassie Blue, comparable amounts of proteins to D. discoideum strains were seen in both of the species (Fig. $3 b$ ). However, EF11 did not detect any proteins in these strains (Fig. $3 a$ ). Alternative methods to obtain fusioncompetent $\mathrm{Dm} 7$ cells by moderate starvation (Filosa \& Dengler, 1972) or cold treatment (Suzuki et al., 1992) were attempted. In neither case were EF-11 reactive proteins detected. Thus, it was concluded that D. mucoroides and $P$. pallidum did not possess gp138, nor proteins sharing the epitope to EF11 with gp138. All the above results of immunostaining are summarized in Table 1. Obvious discreteness is seen between heterothallic and bisexual (typical) strains and homothallic and asexual (atypical) strains of $D$. discoideum and between $D$. discoideum and the other two species.

\section{Discussion}

The cell surface glycoprotein gp138 was previously shown to be responsible for sexual cell fusion between NC4 and HM1, complementary heterothallic strains in D. discoideum (Suzuki \& Yanagisawa, 1989b). The purpose of the present study was primarily to investigate the universality of this protein in order to confirm its importance, and secondly, to determine its relationship to the divergency of mating systems in cellular slime moulds. Our results demonstrated the presence of gp138 as a single protein reactive to EF11, an anti-gp138 monoclonal antibody, in all heterothallic and bisexual strains of $D$. discoideum examined. However, homothallic and asexual strains which had been assigned to $D$. discoideum from morphological criteria did not possess gp138 but were found to contain distinct proteins recognized by EF11. Cell lysates obtained from species other than $D$. discoideum, i.e. $D$. mucoroides and $P$. pallidum contained no EF11-reactive proteins. All these results indicate that gp138 is common among but restricted to cross-matable strains of $D$. discoideum and suggest that molecular mechanisms of sexual cell fusion are variable among cellular slime moulds.

Several recent studies on polymorphisms of protein size (Briscoe et al., 1987) and of restriction fragment length (Evans et al., 1988) suggest that classification of cellular slime moulds based on morphology of fruiting bodies is not appropriate for certain strains. The present results are in striking agreement with these molecular phylogenetic arguments, providing further supportive evidence for each of their claims as follows. Firstly, they reported that homothallic and asexual strains which had been morphologically assigned to $D$. discoideum showed different patterns of polymorphism from heterothallic 
and bisexual strains of $D$. discoideum, and seemed to be remote from typical (heterothallic and bisexual) $D$. discoideum strains. In our study, the former atypical $D$. discoideum strains did not possess gp138 and the latter typical ones possessed gp138. Secondly, however, their results indicated that the homothallic and asexual strains were less different from typical $D$. discoideum strains than were morphologically distinct species such as $D$. mucoroides and $P$. pallidum. The present results showed that the former possessed EF11-reactive proteins, while the latter did not possess any EF11-reactive proteins. In this respect, it may be worth noting that we previously reported that the cell-fusion promoting factor was shared in heterothallic and homothallic systems and suggested that their molecular mechanisms for sexual cell fusion might be similar (Urushihara et al., 1990). Finally, they claimed that, since two homothallic stains, AC4 and ZA3A, were different in protein and nucleic acid polymorphisms and not closely related, they should be assigned to separate species. We further demonstrated that patterns of antigenic proteins reactive to EF11, including the molecular entities correlated with formation of multinucleated cells, were different between AC4 and ZA3A.

One report suggests the possibility that homothallic strains undergo sexual cell fusion with heterothallic ones in $D$. discoideum. Robson \& Williams (1980) obtained macrocysts in the co-culture of homothallic and heterothallic strains. Although their results indicate that homothallic strains can form macrocysts in the presence of heterothallic ones, this does not necessarily mean that sexual cell fusion occurred between those strains. It is also uncertain whether two homothallic strains mutually fuse to produce macrocysts or not. To clarify these points, genetic analyses should be carried out. Because of poor germination of macrocysts, this kind of study has not yet been done, but should ultimately be carried out.

The fact that homothallic and asexual strains did not possess gp138 and that $D$. mucoroides and P. pallidum did not possess any EF11-reactive proteins indicates dissimilarity in mechanisms of sexual cell fusion among those strains. However, it is premature at this stage of research to judge whether or not this is the reason for the absence of cross-mating with typical $D$. discoideum strains. Conversely, the polymorphism of EF11-reactive proteins might itself be the result of the lack of crossmating, as simple accumulation of spontaneouslyoccurring independent changes would be enough to create protein polymorphisms among species without genetic exchange. Further analysis of molecular mechanisms of sexual cell fusion will elucidate these points.

This work was supported by research grants (Nos 01654502 and 01640502) from the Ministry of Education, Science and Culture of
Japan to H. Urushihara. Maintenance and handling of animals were carefully carried out at the Laboratory Animal Research Center of the University of Tsukuba.

\section{References}

Blaskovics, J. C. \& Raper, K. B. (1957). Encystment stages of Dictyostelium. Biological Bulletin 113, 58-88.

Briscoe, D. A., Gooley, A. A., Bernstein, R. L., McKay, G. M. \& Williams, K. L. (1987). Genetic diversity in cellular slime molds: allozyme electrophoresis and a monoclonal antibody reveal cryptic species among Dictyostelium discoideum strains. Genetics 117, 213-220.

CAvender, J. C. \& RAPER, K. B. (1968). The occurrence and distribution of acrasieae in forests of subtropical and tropical America. American Journal of Botany 55, 504-513.

Clark, M. A., Francis, D. \& Eisenberg, R. (1973). Mating types in cellular slime molds. Biochemical and Biophysical Research Communications 52, 672-678.

Erdos, G. W., Raper, K. B. \& Vogen, L. K. (1973). Mating type and macrocyst formation in Dictyostelium discoideum. Proceedings of the National Academy of Sciences of the United States of America 70, $1828-1830$.

ERdos, G. W., Raper, K. B. \& Vogen, L. K. (1975). Sexuality in the cellular slime mold Dictyostelium giganteum. Proceedings of the National Academy of Sciences of the United States of America 72, 970-973.

ERdos, G. W., RaPer, K. B. \& Vogen, L. K. (1976). Effects of light and temperature on macrocyst formation in paired mating types of Dictyostelium discoideum. Journal of Bacteriology 128, 495-497.

EVANS, W. B., Hughes, J. E. \& Welker, D. L. (1988). The use of DNA probes for taxonomic study of Dictyostelium wild isolates. Genetics 119, 561-569.

Filosa, M. F. \& DengleR, R. E. (1972). Ultrastructure of macrocyst formation in the cellular slime mold, Dictyostelium mucoroides: Extensive phagocytosis of amoebae by a specialized cell. Developmental Biology 29, 1-16.

FrancIS, D. (1975). Macrocyst genetics in Polysphondylium pallidum, a cellular slime mould. Journal of General Microbiology 89, 310-318.

Glabe, C. G., Hong, K. \& Vacquier, V. D. (1991). Fusion of sperm and egg plasma membranes during fertilization. In Membrane Fusion, pp. 627-646. Edited by J. Wilschut \& D. Hoekstra. New York: Marcel Dekker.

HERSKOWITZ, I. (1989). A regulatory hierarchy for cell specialization in yeast. Nature, London 342, 749-757.

Hirabayashi, T. (1981). Two-dimensional gel electrophoresis of chicken skeletal muscle proteins with agarose gels in the first dimension. Analytical Biochemistry 117, 443-451.

KiRKPATRICK, M. \& JenKINS, C. D. (1989). Genetic segregation and the maintenance of sexual reproduction. Nature, London 339, 300-301.

KONDRASHOV, A. S. (1988). Deleterious mutations and the evolution of sexual reproduction. Nature, London 336, 435-440.

LAEMMLI, U. K. (1970). Cleavage of structural proteins during the assembly of the head of bacteriophage T4. Nature, London 227, 680-685.

Luporini, P. \& Heckmann, K. (1990). Cell interactions in sexual phenomena. Zoological Science 7 supplement, 89-101.

MacInnes, M. A. \& Francis, D. (1974). Meiosis in Dictyostelium mucoroides. Nature, London 251, 321-324.

Mizutani, A., Hagiwara, H. \& Yanagisawa, K. (1990). A killer factor produced by the cellular slime mold Polysphondylium pallidum. Archives of Microbiology 153, 413-416.

NiCKERSON, A. W. \& RAPER, K. B. (1973). Macrocysts in the life cycle of the Dictyosteliaceae. I. Formation of the macrocysts. American Journal of Botany 60, 190-197.

RoBson, G. E. \& Williams, K. L. (1979). Vegetative incompatibility and the mating-type locus in the cellular slime mold Dictyostelium discoideum. Genetics 93, 861-875.

Robson, G. E. \& Williams, K. L. (1980). The mating system of the cellular slime mould Dictyostelium discoideum. Current Genetics 1 , 229-232. 
Saga, Y., Okada, H. \& Yanagisawa, K. (1983). Macrocyst development in Dictyostelium discoideum. II. Mating-type-specific cell fusion and acquisition of fusion-competence. Journal of Cell Science 60, 157-168.

SIDHU, K. S. \& GuRAYA, S. S. (1991). Current concepts in gamete receptors for fertilization in mammals. International Review of Cytology 127, 253-288.

Sussman, M. (1966). Biochemical and genetic methods in the study of cellular slime mold development. In Methods in Cell Physiology II, pp. 397-410. Edited by D. Prescott. New York: Academic Press.

SusSman, M. \& BosChwITZ, C. (1975). Adhesive properties of cell ghosts derived from Dictyostelium discoideum. Developmental Biology 44, 362-368.

SuzuKI, K. \& Yanagisawa, K. (1989a). Environmental factors inducing sexual development in Dictyostelium discoideum. The Botanical Magazine, Tokyo 102, 53-61.
SUZUKI, K. \& Yanagisawa, K. (1989b). Identification of the cell surface molecule involved in sexual cell fusion of Dictyostelium discoideum. Differentiation 40, 159-165.

Suzuki, K. \& Yanagisawa, K. (1990). Purification and characterization of gp138, a cell surface glycoprotein involved in the sexual cell fusion of Dictyostelium discoideum. Cell Differentiation and Development 30, 35-42.

Suzuki, T., Amagai, A. \& Maeda, Y. (1992). Cyclic AMP and $\mathrm{Ca}^{2+}$ as regulators of zygote formation in the cellular slime mold Dictyostelium mucoroides. Differentiation 49, 127-132.

URUSHIHARA, H. (1992). Sexual development of cellular slime molds. Development Growth and Differentiation 34, 1-7.

Urushihara, H., Saigo, T. \& Yanagisawa, K. (1990). Cell fusion promoting factor common to homothallic and heterothallic mating systems in Dictyostelium discoideum. Development Growth and Differentiation 32, 111-116. 